\title{
THE UTILITY OF THE PECTORALIS MYOCUTANEOUS FLAP IN THE MANAGEMENT OF SELECT CERVICAL ESOPHAGEAL ANASTOMOTIC COMPLICATIONS
}

Richard F. Heitmiller, MD

Shelly J. McQuone, MD

David W. Eisele, MD

\begin{abstract}
Objective: The majority of cervical esophageal anastomotic complications can be successfully managed nonoperatively. A small group of patients may have anastomotic strictures or leakage and fistula formation that are chronic and resistant to nonoperative therapy. The purpose of this study was to review our experience with the use of the pectoralis myocutaneous flap to treat these patients. Methods: Since April 1992, four patients have undergone pectoralis myocutaneous flap repair of cervical esophageal anastomotic complications at our institution. Two patients had chronic strictures, one patient underwent prophylactic repair with a pectoralis myocutaneous flap to prevent stricture formation, and one patient had a chronic anastomotic fistula. The pectoralis myocutaneous flap was harvested in the standard fashion. The technique of anastomotic repair is described. The medical records were retrospectively reviewed to determine patient characteristics and our results. Results: Two suture line leaks developed: one small, contained leak required no intervention, and the other resolved with cervical drainage. Pneumonia, seroma at the site of the pectoralis myocutaneous flap donor, transient hoarseness, and partial skin graft loss occurred in one case each. There were no deaths. Hospital stay ranged from 12 to 22 days. A good functional result was obtained in three patients. Conclusion: Our results show that pectoralis myocutaneous flap repair of select cervical anastomotic complications is safe and well tolerated even in patients with complicated problems. (J Thorac Cardiovasc Surg 1998;115:1250-4)
\end{abstract}

$T^{\text {te }}$ he use of the pectoralis myocutaneous flap (PMF) for head and neck reconstruction is well established as a result of its mobility, skin paddle for epithelial replacement, and well-vascularized muscular tissue. We have found that these attributes make the PMF also useful in the management of select cervical esophageal anastomotic complications. The indications for this operation, the technique, and our results are presented.

From the Departments of Surgery and Otolaryngology Head and Neck Surgery, Johns Hopkins Medical Institutions, Baltimore, Md.

Received for publication July 3, 1997; revisions requested Oct. 6, 1997; revisions received Feb. 9, 1998; accepted for publication Feb. 11, 1998.

Address for reprints: Richard F. Heitmiller, MD, Osler 624, Johns Hopkins Hospital, Baltimore, MD 21287-5674.

Copyright (C) 1998 by Mosby, Inc.

$0022-5223 / 98 \$ 5.00+0 \quad \mathbf{1 2 / 1 / 8 9 4 5 0}$

\section{Patients and methods}

Patients. Since April 1992, four patients have undergone PMF repair of esophageal anastomotic complications. All patients had undergone prior esophageal operations in the management of an acute esophageal injury; in two patients, the initial esophageal operation was performed at an outside hospital, and the patients then were referred to our institution. Two patients had cervical anastomotic strictures that were chronic and unresponsive to endoscopic dilatation or primary surgical revision. One was an esophagocolic anastomotic stricture unresponsive to dilatation and surgical revision in a patient with a history of lye ingestion, and the other was iatrogenic perforation managed first with cervical esophageal diversion and later by end-to-end esophagoesophagostomy. In one patient with a long-segment lye-induced esophageal stricture, the cervical esophagogastric anastomosis was prophylactically widened with a PMF to prevent anastomotic stricturing. The last patient had a benign, spontaneous, intrathoracic perforation that was managed by staged esophagectomy and later by substernal gastric pull-up and esophagogastric cervical anastomosis. The left corner of the manubrium sternum and the left clavicular head were removed as part of that procedure. The patient was quite thin with little soft tissue coverage over the anastomosis. An anastomotic leak developed and per- 
sisted despite attempts at reexploration and primary closure. All PMF reconstructive operations were performed at The Johns Hopkins Hospital. The medical records were retrospectively reviewed to determine patient characteristics, initial esophageal injury, technique of surgical esophageal repair, nature of the subsequent esophageal anastomotic complication that led to PMF repair, and outcome.

Technique. General endotracheal anesthesia is used, and the patient is positioned supine with the neck in slight extension. The previous cervical incision (usually leftsided) is reopened, and the cervical esophagus is exposed anterior and medial to the carotid sheath contents. The esophageal anastomosis is identified and the location and extent of the anastomotic stricture or fistula is determined. Intraoperative endoscopy may be used if needed to locate the abnormality and define its limits. If additional exposure is required, the skin incision is extended inferiorly in the midline, and an upper sternal split is performed. Insertion of a pediatric chest retractor to spread the divided manubrium sternum optimizes cervicomediastinal exposure. Only after it is confirmed that the stricture or fistula may be managed with PMF reconstruction is the ipsilateral flap harvested.

The skin pedicle of the PMF is designed in a fusiform or elliptic shape overlying the inferior aspect of the pectoralis major muscle (Fig. 1). The width of the flap is tailored to the length and diameter of the anastomotic stricture. In female patients, the skin pedicle is often positioned in the inframammary crease to better conceal the donor scar. The dermis of the skin pedicle is sutured to the muscle fascia to prevent disruption of its blood supply. An oblique incision is made from the superolateral corner of the skin pedicle incision to the axilla, circumferential subcutaneous skin flaps are raised, and the exposed pectoralis muscle is elevated to the level of the clavicle, preserving its blood supply, the thoracoacromial artery and vein. The muscle is denervated in this process, resulting in subsequent muscular atrophy. The muscle flap is divided medially and laterally. A subcutaneous tunnel is created over the clavicle connecting the chest and neck wounds. The tunnel must be wide enough to allow passage of the flap into the neck without vascular compromise. The chest incision is closed primarily over closed suction drains.

A stricture is managed in this way: The esophagus is opened longitudinally through the stricture into normalcaliber lumen proximally and distally. The PMF skin pedicle is trimmed to match the defect. The flap is inverted so that the skin side is facing into the esophageal lumen and then sewn in place with interrupted, inverting sutures (Fig. 2). A nasogastric tube is directed across the opening under direct vision before the patch closure is completed (Fig. 3). The overlying pectoralis muscle is sutured as a second-layer closure. A fistula is managed in this way: The opening is debrided back to healthy bowel wall, and the PMF skin paddle is trimmed to appropriate size, inverted, and sewn in place to patch the defect as described earlier. The cervical or cervicomediastinal incision is then closed primarily in layers if possible. When the neck incision cannot be closed primarily because of inadequate mobility of cervical wound skin edges or bulkiness

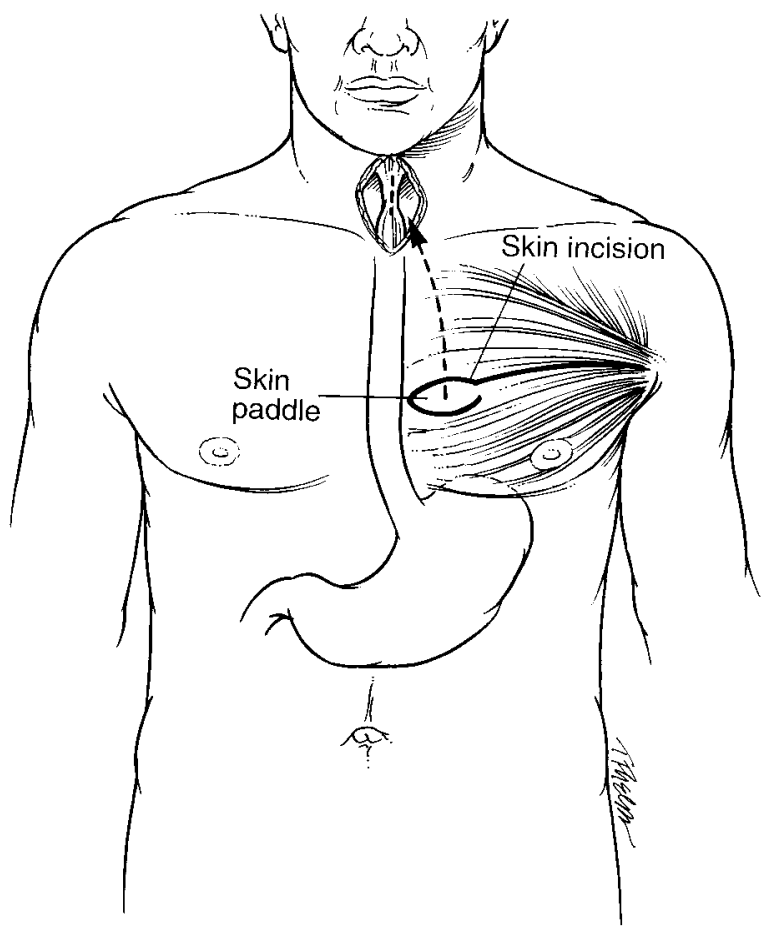

Fig. 1. The location of the PMF incisions and skin pedicle in relation to the cervical incision is shown.

of the PMF flap, there are two options. The first is to harvest a PMF with a larger skin pedicle, which is then split and folded, providing epithelial replacement intraluminally as well as cutaneously. The second option is to skin graft the exposed PMF muscle.

The postoperative management with regard to perioperative antibiotics, wound care, nasogastric drainage, and resumption of oral feedings is identical to the management of a standard esophageal anastomosis.

\section{Results}

There were two men and two women whose ages ranged from 37 to 80 years. Initial esophageal injury was lye ingestion in two, spontaneous perforation in one, and endoscopic perforation in one. Three patients had staged esophageal repair and reconstruction. Esophageal reconstruction involved stomach in two, colon in one, and primary anastomosis in one. Indications for PMF reconstruction were chronic recurrent stricture in two, chronic fistula in one, and prophylaxis to prevent anastomotic stricture in one (Table I).

Results are summarized in Table II. Two anastomotic leaks developed. One was a small contained leak that was detected on routine postoperative contrast esophagogram and necessitated no treat- 


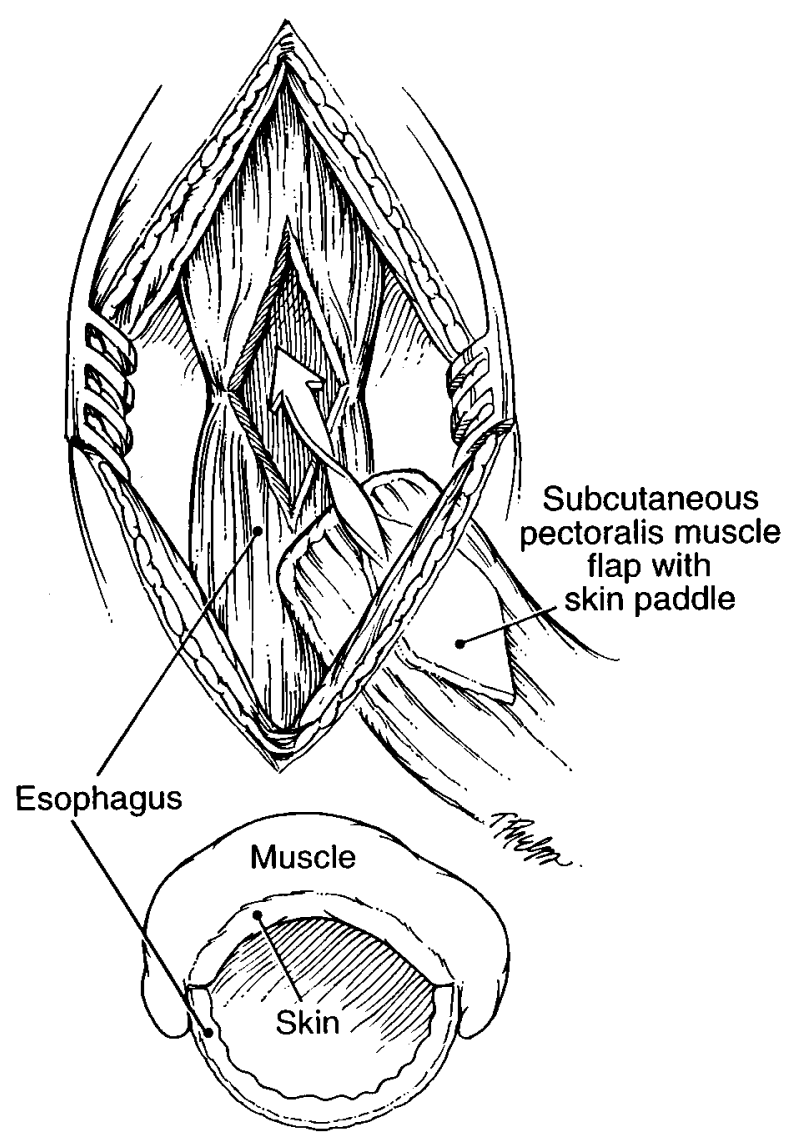

Fig. 2. Diagrammatic summary of the PMF technique. The flap is tunneled into the cervical field, inverted, and the skin pedicle is used to widen the esophageal lumen as shown in the cross-sectional view. The accompanying pectoralis muscle secondarily reinforces the repair.

ment. The other necessitated cervical wound opening, withholding oral intake, and cervical wound dressings until the leak closed spontaneously. Other complications included one case each of pneumonia, pectoralis muscle donor site wound seroma, transient hoarseness, and partial skin graft loss, which resolved with local dressings. There were no deaths. The length of hospital stay ranged from 12 to 22 days.

In three patients the functional result has been good, allowing patients to eat soft solid or regular solid food without the need for nutritional support. In one patient, the PMF technique was successful at opening the anastomotic stricture, but the functional result was poor because of antiperistaltic colon interposition, which caused functional obstruction and profound biliary reflux. No patient required postoperative esophageal dilatations.

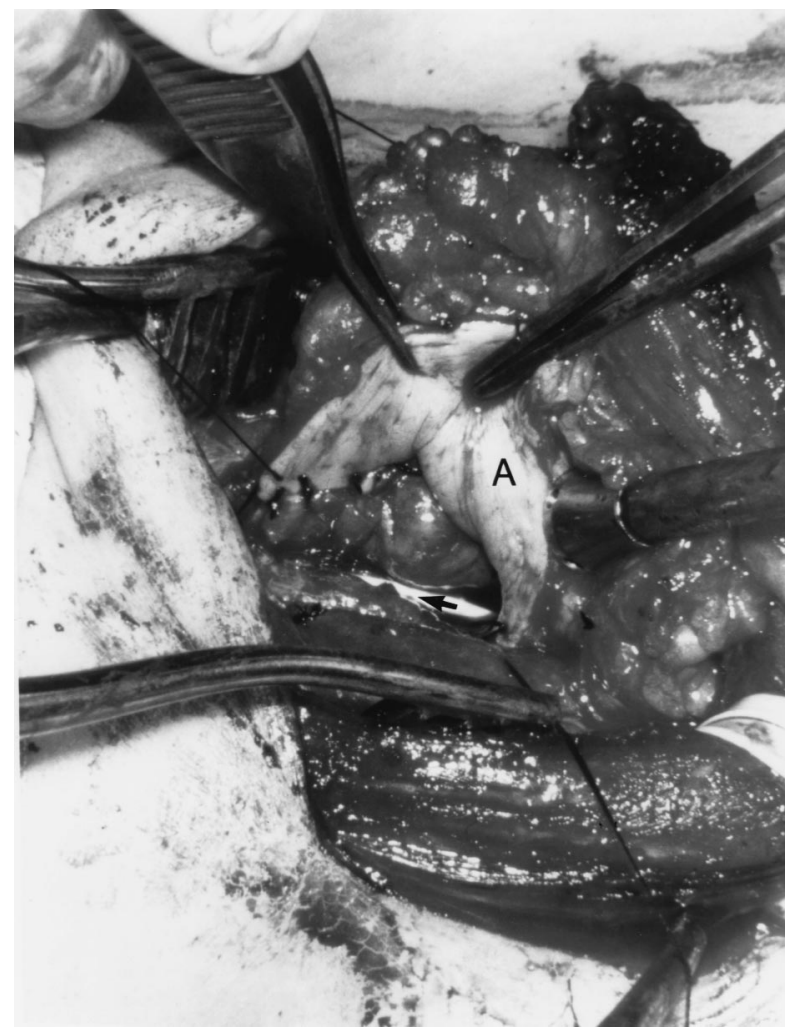

Fig. 3. The anastomotic stricture is widened by patching the narrowed segment with the PMF, which is oriented so that the skin surface faces intraluminally as shown $(A)$. The arrow on the nasogastric tube is oriented from proximal to distal.

\section{Discussion}

The utility of the pectoralis myocutaneous flap for head and neck reconstruction is well established as a result of its mobility, skin pedicle for epithelial replacement, and well-vascularized muscular tissue. ${ }^{1-4}$ This flap has traditionally been used for pharyngeal reconstruction in patients with malignant disease of the upper aerodigestive tract. ${ }^{2} \mathrm{We}$ believe that these same features make it ideally suited for correction of select cervicomediastinal esophageal anastomotic complications as well.

Indications for PMF reconstruction are chronic cervical esophageal anastomotic strictures unresponsive to bouginage and anastomotic leak with a chronic cutaneous fistula. Strictures after cervical esophageal anastomosis are well documented and have a reported frequency of $14 \%$ to $42 \% .^{5-12}$ The majority of these strictures are successfully managed with esophageal bouginage and do not require surgical revision. ${ }^{13}$ In contrast, in a small group of 
Table I. Patient characteristics

\begin{tabular}{ccccc}
\hline Patient & Age/sex & Esophageal injury & Esopghageal reconstruction & Anastomotic complication \\
\hline 1 & $73 / \mathrm{M}$ & Spontaneous perforation & $\begin{array}{c}\text { Staged esophagectomy, substernal gastric } \\
\text { pull-up, cervical anastomosis } \\
\text { Staged esophagectomy, substernal colon } \\
\text { interposition, cervical anastomosis } \\
\text { Single-stage esophagectomy, gastric pull-up, } \\
\text { cervical anastomosis with flap anastomoplasty } \\
\text { Staged cervical esophagostomy (diversion); } \\
\text { end-to-end esophagoesophagostomy }\end{array}$ & Lye ingestion \\
4 & $57 / \mathrm{F}$ & Lye ingestion & Iatrogenic perforation & Recurrent stricture \\
\hline
\end{tabular}

Table II. Surgical results

\begin{tabular}{|c|c|c|c|c|c|}
\hline Patient & Anastomotic leak & Other morbidity & Death & $\operatorname{LOS}$ (days) & Result \\
\hline 1 & Small, contained & Pneumonia, wound seroma & No & 22 & Eating solid foods; weaning TFs \\
\hline 2 & $\begin{array}{l}\text { Yes, closed with } \\
\text { dressings }\end{array}$ & None & No & 12 & $\begin{array}{l}\text { Anastomosis open, poor colon emptying; } \\
\text { TFs needed }\end{array}$ \\
\hline 3 & None & Transient hoarseness & No & 17 & $\begin{array}{l}\text { Early postop. anastomotic dilatations needed; } \\
\text { now eating solids, no TFs }\end{array}$ \\
\hline 4 & None & $\begin{array}{l}\text { Partial loss of STSG, which } \\
\text { resolved with dressings }\end{array}$ & No & 15 & $\begin{array}{l}\text { Mild anastomotic narrowing; eating soft solids, } \\
\text { no TFs }\end{array}$ \\
\hline
\end{tabular}

$L O S$, Length of stay; $T F$, tube feeding; $S T S G$, split-thickness skin graft.

patients there is an intrinsic esophageal abnormality resulting from lye ingestion, radiation exposure, or postoperative fibrosis, which predisposes to severe, recurrent postanastomotic stricturing. Orringer ${ }^{14}$ has underscored the difficulty in managing anastomotic strictures after transhiatal esophagectomy for lye-induced esophageal injuries. These strictures are difficult to dilate and are susceptible to rapid, symptomatic recurrence. The advantages of using the PMF technique to manage this small subgroup of strictures are that it does not require segmental bowel resection, it uses well-vascularized epithelium to patch open the stricture, and it provides generous soft tissue coverage. Further, cervical exposure, even with upper sternal split if needed, is generally well tolerated by patients.

Cervical anastomotic leak with chronic cutaneous fistulization is uncommon. It is most likely to occur after substernal esophageal bypass in which the esophageal anastomosis is superficial with insufficient soft tissue coverage. Orringer ${ }^{14}$ reported the cervical esophageal leak rate to be almost eight times higher if a substernal bypass route is used. Primary repair without flap reconstruction is difficult given the inability to mobilize wound edges for tension-free closure, the potential for nonviable tissue at the leak site, and poor soft tissue coverage of the repair site.

The PMF is harvested in a standard fashion. The size and shape of the epithelial pedicle can be individualized to the size of the defect to be repaired. The donor site is closed primarily; the recipient site is managed by primary closure, splitthickness skin grafting, or splitting and "folding" of the epithelial tissue so that part of the skin pedicle is used to patch the esophageal defect and the rest is used for external wound closure. The procedure is usually done after an anastomotic complication has occurred, although it may be done prophylactically in patients who are at risk for significant anastomotic complications, as was done in one of our patients. Postoperative management with respect to wound care and resumption of oral feedings is identical to that used with a standard esophageal anastomosis. There are a few contraindications to PMF use. These include disruption of its vascular pedicle from trauma or a previous operation or injury to the chest wall dermis that would be used as the skin pedicle.

A variety of other techniques have been reported to manage pharyngeal and esophageal anastomotic complications. Free tissue transfer from the radial forearm or other donor sites is a reasonable alternative for reconstruction of refractory strictures, especially in morbidly obese patients in whom flap thickness limits the use of the PMF and in patients who are opposed to a donor-site chest wall scar. ${ }^{15,16}$ Frimpong-Boateng ${ }^{17}$ reported on four patients whose cervical esophageal anastomotic strictures were managed with a sternocleidomastoid myocuta- 
neous flap using a technique similar to what we describe. In their small series, there were no suture line leaks or recurrent strictures. Others, however, have condemned the use of the sternocleidomastoid myocutaneous flap because of its poor reliability as a result of a random blood supply and a reported flap necrosis rate of greater than $50 \% .^{18,19}$ The reliability of the sternocleidomastoid myocutaneous flap is improved when combined with an ipsilateral platysmal flap, ${ }^{20}$ but at the cost of increased flap bulk, reduced flap mobility, and compromise of carotid sheath soft tissue coverage. Use of the latissimus dorsi flap has also been described. ${ }^{21}$ The dependability of this flap is attributed to its excellent blood supply from the thoracodorsal artery. Like the PMF, the latissimus dorsi donor site is closed primarily. However, unlike the PMF, use of the latissimus dorsi flap requires separate operative positioning of the patient.

Our results show that this procedure is safe and well-tolerated even in this group of patients with complicated abnormalities. There were no deaths and only one free suture-line leak, which healed with drainage and dressings without subsequent stricturing. One patient had pneumonia before resuming oral intake, which responded to treatment. One flap donor site complication developed, a seroma, which was successfully managed by insertion of a closed-suction drain. One patient required transient postoperative anastomotic dilatations; she is now eating solid food without the need for dilatations or enteral supplementation. The only poor functional result was in a patient whose anastomosis was successfully open but who had a poorly emptying antiperistaltic colon interposition.

\section{REFERENCES}

1. Sessions DG, Cummings CW, Weymuller EA Jr, Makielski KH. Pectoralis myocutaneous flap. In: Sessions DG, Cummings $\mathrm{CW}$, Weymuller EA Jr, Makielski KH, editors. Atlas of access and reconstruction in head and neck surgery. St. Louis: Mosby; 1992. p. 249-53.

2. Cusumana RT, Silver CE, Braner RJ, et al. Pectoralis myocutaneous flap for reconstruction of cervical esophagus. Head Neck 1989:11:450-6.

3. Kroll SS, Goepfort H, Jones M, et al. Analysis of complications in 168 pectoralis major myocutaneous flaps used for head and neck reconstruction. Ann Plast Surg 1990;25:93-7.

4. Shah JP, Haribhakti V, Loree TR, et al. Complications of pectoralis major myocutaneous flaps in head and neck reconstruction. Am J Surg 1990;160:352.

5. Honkoop P, Siersema PD, Tilanus HW, Stassen LPS, Hop WCJ, van Blankenstein M. Benign anastomotic strictures after transhiatal esophagectomy and cervical esophagogastrostomy: risk factors and management. J Thorac Cardiovasc Surg 1996;111:1141-8.

6. Orringer MB, Marshall B, Stirling MC. Transhiatal esophagectomy for benign and malignant disease. J Thorac Cardiovasc Surg 1993;105:265-77.

7. Inagake M, Yamane T, Kitao Y, et al. Balloon dilatation for anastomotic strictures after upper gastro-intestinal surgery. World J Surg 1992;16:541-4.

8. Bardini R, Bonavina L, Asolati M, Ruol A, Castoro C, Tiso E. Single-layered cervical esophageal anastomoses: a prospective study of two suturing techniques. Ann Thorac Surg 1994;58:1087-90.

9. Piere JPEN, de Graaf PW, Poen H, van der Tweel I, Obertop $\mathrm{H}$. Incidence and management of benign anastomotic stricture after cervical oesophagogastrectomy. Br J Surg 1993;80: 471-4.

10. Dewar L, Gelfand G, Finley RJ, Evans K, Inculet R, Nelems B. Factors affecting cervical anastomotic leak and stricture formation following esophagogastrectomy and gastric tube interposition. Am J Surg 1992;163:484-9.

11. Lam TCF, Fok M, Cheng SWK, Wong J. Anastomotic complications after esophagectomy for cancer: a comparison of neck and chest anastomoses. J Thorac Cardiovasc Surg 1992;104:395-400.

12. Fok M, Ah-Chong AK, Chenh SWK, Wong J. Comparison of a single layer continuous hand-sewn method and circular stapling in 580 oesophageal anastomoses. Br J Surg 1991;78: 342-5.

13. Skinner DB, Belsey RHR. Nonoperative treatment of esophageal obstruction, including bougienage. In: Skinner DB, Belsey RHR, editors. Management of esophageal disease. Philadelphia: WB Saunders; 1988. p. 133.

14. Orringer MB. Surgical options for esophageal resection and reconstruction. In: Baue AE, Geha AS, Laks H, Hammond GL, Naunheim KS, editors. Glenn's thoracic and cardiovascular surgery, 6th ed. New York: Appleton and Lange; 1996. p. 899-922.

15. Chen H, Tang Y, Noorhoff MS. Patch esophagoplasty with free forearm flap for focal stricture of the pharyngoesophageal junction and cervical esophagus. Plast Reconstr Surg 1992;90:45-52.

16. Evans GRD, Schusterman MA, Kroll SS, et al. The radial forearm free flap for head and neck reconstruction: a review. Am J Surg 1994;168:446-50.

17. Frimpong-Boateng K. Sternocleidomastoid myocutaneous esophagoplasty. Eur J Cardiothorac Surg 1994;8:660-2.

18. Tiwari R. Experiences with the sternocleidomastoid muscle and myocutaneous flaps. J Laryngol Otol 1990;104:315-21.

19. Larson DL, Goepfert H. Limitations of the sternocleidomastoid musculocutaneous flap in head and neck cancer reconstruction. Plast Reconstr Surg 1982;70:328-35.

20. Sessions DG, Cummings CW, Weymuller EA Jr, Makielski KH. Platysma myocutaneous flap. In: Sessions DG, Cummings CW, Weymuller EA Jr, Makielski KH, editors. Atlas of access and reconstruction in head and neck surgery. St Louis: Mosby; 1992. p. 233-7.

21. Chen H, Tang Y, Noordhoff MS. Patch esophagoplasty with musculocutaneous flaps as treatment of complications after esophageal reconstruction. Ann Plast Surg 1987;19:448-53. 